\title{
Prices, peers, and perceptions (P3): study protocol for improved biomass cookstove project in northern Ghana
}

Katherine L. Dickinson ${ }^{1 *}$ (D), Maxwell Dalaba ${ }^{2}$, Zachary S. Brown ${ }^{3}$, Rex Alirigia ${ }^{4}$, Evan R. Coffey ${ }^{4}$, Elise Mesenbring ${ }^{4,5}$, Manies Achazanaga ${ }^{2}$, Desmond Agao ${ }^{2}$, Moro Ali², Ernest Kanyomse², Julius Awaregya ${ }^{5}$, Clifford Amoah Adagenera ${ }^{5}$, John Bosco A. Aburiya ${ }^{5}$, Bernard Gubilla ${ }^{5}$, Abraham Rexford Oduro ${ }^{2}$ and Michael P. Hannigan ${ }^{4}$

\begin{abstract}
Background: Despite their potential health and social benefits, adoption and use of improved cookstoves has been low throughout much of the world. Explanations for low adoption rates of these technologies include prices that are not affordable for the target populations, limited opportunities for households to learn about cookstoves through peers, and perceptions that these technologies are not appropriate for local cooking needs. The P3 project employs a novel experimental design to explore each of these factors and their interactive effects on cookstove demand, adoption, use and exposure outcomes.

Methods: The P3 study is being conducted in the Kassena-Nankana Districts of Northern Ghana. Leveraging an earlier improved cookstove study that was conducted in this area, the central design of the P3 biomass stove experiment involves offering stoves at randomly varying prices to peers and non-peers of households that had previously received stoves for free. Using household surveys, electronic stove use monitors, and low-cost, portable monitoring equipment, we measure how prices and peers' experience affect perceptions of stove quality, the decision to purchase a stove, use of improved and traditional stoves over time, and personal exposure to air pollutants from the stoves.

Discussion: The challenges that public health and development communities have faced in spreading adoption of potentially welfare-enhancing technologies, like improved cookstoves, have highlighted the need for interdisciplinary, multisectoral approaches. The design of the P3 project draws on economic theory, public health practice, engineering, and environmental sciences, to more fully grasp the drivers and barriers to expanding access to and uptake of cleaner stoves. Our partnership between academic institutions, in the US and Ghana, and a local environmental nongovernmental organization creates unique opportunities to disseminate and scale up lessons learned.
\end{abstract}

Trial registration: ClinicalTrials.gov NCT03617952 7/31/18 (Retrospectively Registered).

Keywords: Cookstoves, Household air pollution, Behavior change, Global health, Study protocol

\footnotetext{
* Correspondence: katherine.dickinson@ucdenver.edu

${ }^{1}$ Colorado School of Public Health, University of Colorado Anschutz Medical

Campus, 13001 E 17th PI, Aurora, CO 80045, USA

Full list of author information is available at the end of the article
}

(c) The Author(s). 2018 Open Access This article is distributed under the terms of the Creative Commons Attribution 4.0 International License (http://creativecommons.org/licenses/by/4.0/), which permits unrestricted use, distribution, and reproduction in any medium, provided you give appropriate credit to the original author(s) and the source, provide a link to the Creative Commons license, and indicate if changes were made. The Creative Commons Public Domain Dedication waiver (http://creativecommons.org/publicdomain/zero/1.0/) applies to the data made available in this article, unless otherwise stated. 


\section{Background}

Low adoption rates of technologies with the potential to improve public health have been observed in a number of cases across a variety of contexts; examples include bed nets [1], latrines [2], deworming drugs [3], and condoms [4], among many others. Explanations for this phenomenon tend to focus on three key factors: the prices of these technologies and the role of subsidies [1, $5,6]$, the effect of peers and social learning [3, 7, 8], and the ways in which users' perceptions of technologies are influenced by different factors and affect subsequent adoption decisions $[3,6,9]$. The aim of this study is to investigate the interactions among these three factors in determining adoption of improved cookstoves, a technology with potential public health, social, and environmental benefits.

Cooking with biomass over open fires is a widespread practice throughout much of the developing world. Wood, dung, agricultural residues, and charcoal produce large amounts of respirable particles, carbon monoxide, and other toxic pollutants when used to fuel simple cooking stoves [10]. A growing body of evidence links household air pollution (HAP) to acute lower respiratory infections in young children and chronic obstructive pulmonary disease and lung cancer (for coal) in adults [1113]. Biomass cooking also impacts regional and global climate through black carbon particulates and other emissions [14]. Furthermore, gathering fuels is a time-consuming activity in locations where environmental damage has often already made resources scarce. This time burden, which falls disproportionately on women, could be better spent on domestic care or income-generating activities, aggravating the problem of "time poverty" [15].

While a multitude of technologies exist that could potentially address the suite of problems linked to current biomass cooking practices, efforts to disseminate these technologies and promote changes in cooking behaviors have often fallen short $[16,17]$. The Global Alliance for Clean Cookstoves, a public-private partnership currently in its second phase of "investment and innovation," has set a goal to foster the adoption of clean cookstoves and fuels in 100 million households by 2020 [18]. However, consistent adoption of cleaner stoves has proven elusive in practice at larger, community-level scales. The well-known RESPIRE study provided an improved chimney woodstove to households in highland Guatemala and saw encouraging results, finding a significant reduction in carbon monoxide exposure for groups receiving the clean stove over an 18 month period [19]. On the other hand, randomized trials of a locally-made mud stove in India achieved disappointing initial adoption and maintenance rates and, in the long run, failed to reduce exposure to dangerous air pollutants [16]. These authors specifically contrasted their intervention with the RESPIRE study and argued that they provided households with greater ability to reveal their valuation in usage rates: stoves were locally made and significantly cheaper, were not inspected weekly [20], and were followed for a longer period of time. In response, the RESPIRE study's lead investigator argued that the Indian "improved" stove was not truly an improvement over existing technologies since it failed to alter combustion and reduce smoke in any meaningful way [21]. Essentially, both sides of this debate contended that low perceived benefits of the cookstove technology led to low adoption and use. The cookstove example thus presents itself as a useful context for examining the challenges and dynamics of technology adoption.

\section{Prior research on technology adoption}

Technology adoption continues be a central research topic in public health and social sciences because of its importance in understanding development and health outcomes and because of the kaleidoscope of models explaining different economic, psychological, and sociological factors at play. Two key strands of literature we summarize here examine the roles of prices and peer effects on technology adoption.

\section{Prices and technology adoption and use}

Setting subsidy and end-user price levels for a new technology requires grappling with a fundamental tension between rapid diffusion and sustainability [22, 23]. On the one hand, subsidizing adoption of socially beneficial technologies may be necessary to promote widespread adoption, at least in the short-run. Indeed, recent evidence has shown that new technologies offered at a positive price tend to exhibit much lower demand than identical products offered for free $[24,25]$. In one example that is particularly relevant for this study, Mobarak and coauthors [23] analyze a field experiment with the distribution of cookstoves in Bangladesh. The researchers find demand for these modern stoves to be extremely price elastic, with only $5 \%$ of households purchasing the stoves with no discount and a 50\% discount yielding 8$12 \%$ higher demand (relative to the full cost treatment).

On the other hand, many argue that goods given away for free or at low cost will be used at lower rates than goods for which users pay higher prices. Economic theory offers at least two mechanisms for this hypothesis. First, price-based incentives for new technologies (or any scarce good) ensure allocation of goods to those valuing them the most (a basic principle in economics). Second, higher prices may lead potential users to perceive that a product is of higher quality [26], thus encouraging higher use. Empirically, however, there is little evidence to support this hypothesized positive relationship between price and technology use. In one of the 
few studies to directly test this hypothesis, Cohen and Dupas [1] analyze data from a randomized controlled trial of bednet distribution in Kenya in which health clinics distributed nets freely or partially subsidized at four different end-user price levels (between $\$ 0.15$ and $\$ 0.60$ per net). The researchers identify significantly price-elastic demand for bednets: Clinic patients charged the highest price in the experiment exhibited 60\% lower demand for bednets relative to the free distribution group. Moreover, despite thorough statistical analysis, Cohen and Dupas do not find evidence that the free distribution group exhibits lower usage rates (conditional on ownership) than the partially subsidized groups. Furthermore, the free distribution group is the only treatment group for which the researchers find a statistically significant health impact (reduced anemia). To our knowledge, these authors did not directly examine the relationship between price and perceived quality of bednets as an intermediate factor affecting product use.

Thus, empirical evidence to date seems to indicate that highly subsidized or free distribution of health-promoting technologies: a) may be required to promote their initial adoption, and b) does not appear to reduce subsequent technology use (although the latter finding has a thinner evidence base and should be tested more broadly). Yet free distribution strains public resources and may not be sustainable over time or scalable to population-level technology diffusion. Additional work is thus required to examine the dynamics of diffusion over time and space. One particular question involves the possibility that subsidizing adoption to an initial group of users can lead that group's peers to learn about and subsequently adopt a technology and, assuming the technology is useful, positively affect individuals' willingness to pay (WTP) for the technology.

\section{Peer effects and technology adoption}

Peer effects present the possibility of a positively reinforcing feedback for sustaining adoption and takeoff of new technologies. The power of social contagion in technology adoption has been measured in a number of contexts [e.g., 27]. Miller and Mobarak [9] estimate peer effects on efficient cookstove adoption in Bangladesh, by conducting randomized, sequential cookstove rollout first with opinion leaders, then with a first round of randomly selected members of the general population (in the same neighborhoods as the opinion leaders), and then with social contacts of the first round households. Their results suggest statistically significant and positive peer effects from opinion leaders' adoption behaviors (at least in some cases), but social ties to first round participants are found to reduce the likelihood of adoption among second round households. The authors' interpretation of this finding is that second round participants held initially high expectations about the modern stoves, and revised these expectations downward via information from social contacts. This negative peer effect finding and its interpretation are similar to Kremer and Miguel's [3] analysis of deworming drugs in Kenya. Yet to our knowledge, neither study explicitly measured expectations or beliefs about product quality. Both of these cases highlight the fact that while the increasing availability of experimental data and appropriate econometric methods for analyzing these data have gone a long way toward solving Manski's [28] "reflection problem" and enabling identification of peer effects, this research has also raised a number of new questions about the causal mechanisms underlying observed effects.

In light of the previous research outlined above, we aim to contribute to a more scientific understanding of the interactions between economic incentives ("prices"), social learning ("peers"), and subjective beliefs ("perceptions") in technology adoption dynamics. Specifically, we posit that prices and peer effects both operate - at least in part - through separate and interactive effects on perceptions of a technology's quality and benefits.

\section{Conceptual model}

Figure 1 presents our conceptual model using an influence diagram of how we expect prices, peers, and perceptions to interact, based on previous research. Prices can be expected to have both direct and indirect influences on key outcomes (technology adoption and use): The direct effect (the economic "law of demand") is expected to be negative, while it is possible that there is a positive indirect effect on both adoption and use via higher perceptions of technology benefits for higher-priced products. Peer effects can be expected to affect individual adoption and use through effects on individuals' perceived value of the new technology. This effect can be negative or positive.

Importantly, the conceptual model in Fig. 1 also highlights the potential feedbacks (the dashed arrows) that can confound causal identification, and which our experimental design seeks to address. First, a number of factors determine prices for a new technology in an observational setting, including supply and retail costs. We will address this confounding feedback using prices which are randomly assigned across groups of households. Second, peer effects are well-recognized for their potential to generate positive feedback loops. We will control for this confounder by sampling households neighboring participants in the previous study's cookstove intervention, in conjunction with the recruitment of new groups of households unexposed to the technology. This identification strategy for peer effects appears unique compared to previous research [3, 9, 29]. 


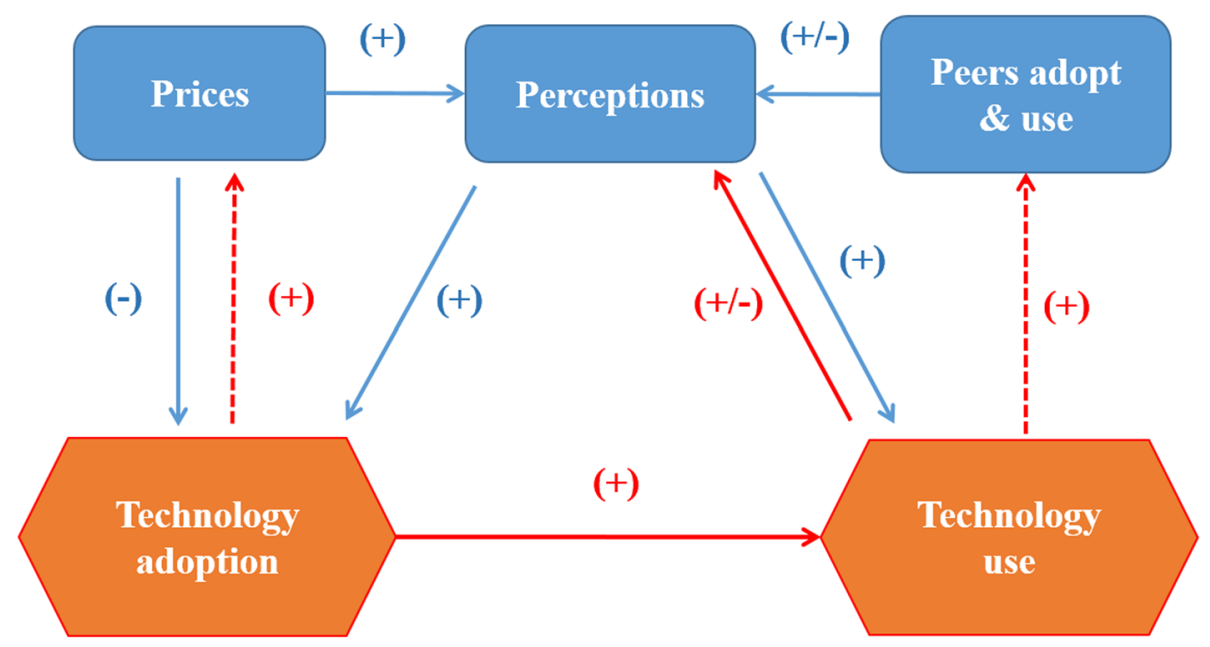

Fig. 1 Influence diagram showing technology adoption dynamics. The solid arrows in the diagram are influences that this study will examine in detail. The dashed arrows are potential confounding feedbacks that our identification strategy will address. The signs in parentheses indicate whether effects are expected to be positive or negative, based on previous literature

Finally, an important question for sustainability science and public health is how subjective expectations change following technology adoption and subsequent use, and how these revised expectations determine long-term use. For example, we might hypothesize (e.g. based on the Prospect Theory literature [30]) that discovering a new technology to yield smaller than expected benefits may be have a greater downside effect on usage than the upside effect of finding the technology to have greater than expected benefits.

Additional key questions emerging from this model are how the individual factors affecting key outcomes of interest are mediated by the other factors. A standout issue along these lines is the possibility that peer effects

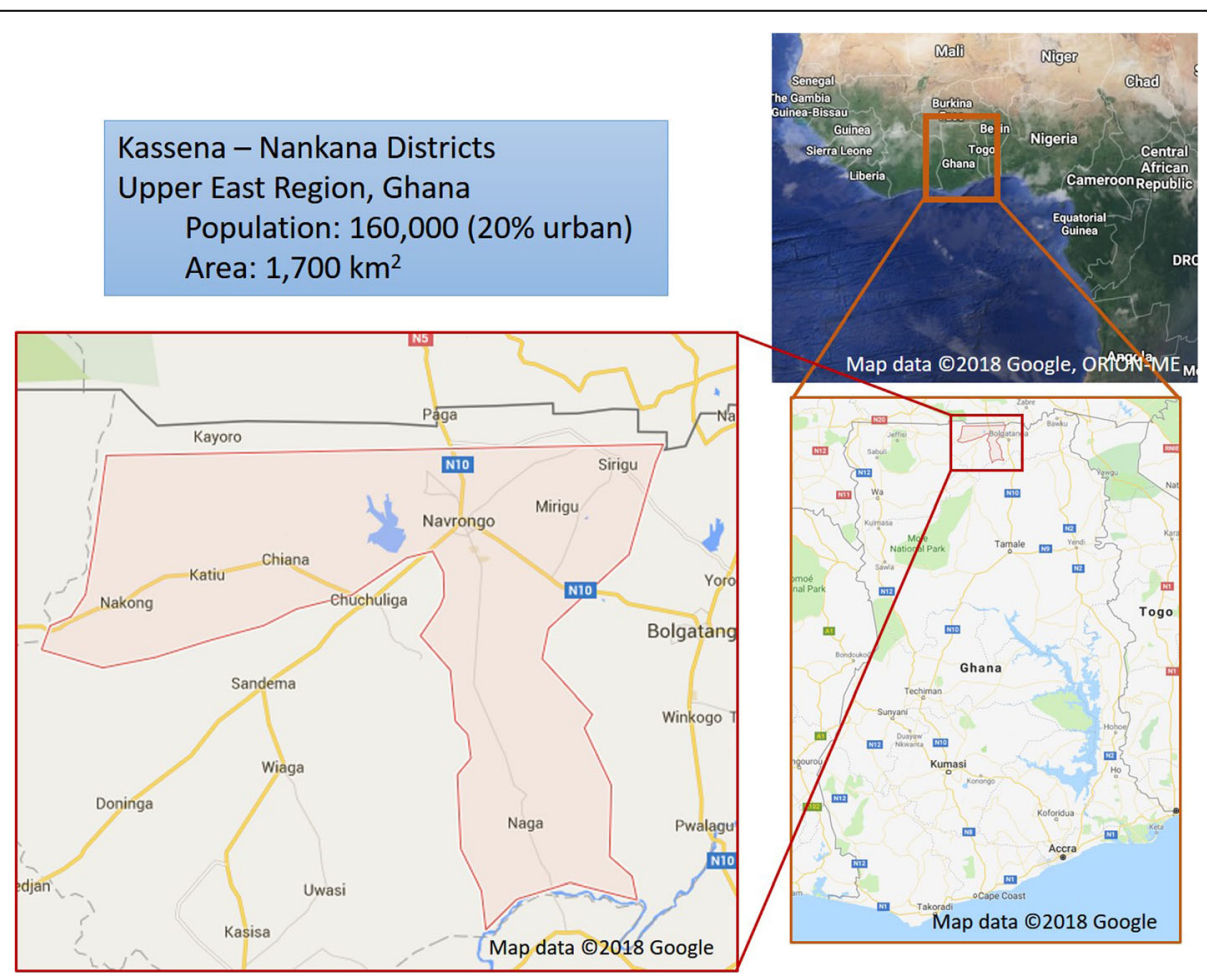

Fig. 2 Map of the study area. Source: Authors' creation with map and imagery data from Google, ORION-ME, Data SIO, NOAA, U.S. Navy, NGA, GEBCO, Landsat/Copernicus, U.S. Geological Survey, IBCAO 
may dampen the role of prices in subjective perceptions of technology quality. This is one hypothesis suggested by Ashraf et al. [6], who conducted an information-based interventions in the case of improved water filter subsidization in Zambia and found that information provision increased the price elasticity of demand, making price subsidies more effective. The authors remain agnostic on the causal mechanisms behind this finding, but suggest that uninformed consumers may use price as an indicator of product quality.

\section{Methods and study design \\ Study area}

The P3 study takes place in the Kassena-Nankana Districts (KND) in Northern Ghana (Fig. 2). The climate in this region is hot and arid, with one rainy season lasting from approximately May to October, and the vegetation is dominated by woody shrubs and grassland. Much of the land is used in subsistence agriculture, with millet as the dominant crop. Since 1993, the Navrongo Health Research Centre (NHRC) has conducted a district-wide Health and Demographic Surveillance Survey (HDSS) [31]. According to HDSS data, the total population of the KND is about 156,000 (roughly 30,000 households), with about $80 \%$ living in areas classified as rural while $20 \%$ are in more urban areas, primarily in and around the central town of Navrongo. Eighty eight percent of rural households report using biomass (wood or agricultural waste) as their main cooking fuel, while another $9 \%$ rely primarily on charcoal, and only about $3 \%$ of households cook primarily with gas or electricity. The traditional cooking method in these rural areas is a three-stone open fire, with many households also using charcoal stoves. Cooking is done both indoors and outdoors. Ghana has one of the highest deforestation rates in Africa with the country's forest an estimated quarter of its original size [32].

\section{Prior research: The REACCTING study}

The P3 project builds on an earlier cookstove study that our research team conducted in this region, the Research on Emissions, Air Quality, Climate, and Cooking Technologies in Northern Ghana (REACCTING) study [33]. The primary objective of the REACCTING study was to assess the effectiveness, feasibility, and sustainability of scaling up use of improved cookstoves in Northern Ghana through a coupled natural-human systems approach that explores the linkages among human behaviors (i.e., cooking practices), detrimental air quality at multiple spatial and temporal scales, and health outcomes (respiratory illness).

For the purposes of the P3 project, the key feature of the REACCTING study was a randomized household-level intervention which distributed two types of improved biomass stoves for free to 200 participating households in the rural areas of the KND. Based on extensive feedback from households in the KND that tested several stove models during a pilot phase (2012-2013), two different stove technologies were selected for the REACCTING intervention study: the Gyapa Woodstove and the Philips Smokeless Woodstove (HD4012). The Gyapa Woodstove was specifically designed for use by populations in the Northern Regions of Ghana by Relief International/Gyapa Enterprises. A similar model was used in a past intervention study in Accra, and saw significant decreases in kitchen $\mathrm{CO}$ and PM2.5 levels [34]. This model includes a combustion chamber, often called a rocket-stove design, with a ceramic liner on the inside and an outer liner of insulation and sawdust to increase heat retention. Meanwhile, the Philips stove was a gasifier stove produced in Lesotho. This stove was visually perceived as "high-tech," required power (supplied, in our context, through a small solar panel) to perform properly, and had been observed to be a low emitting technology, Tier 3 stove, during lab testing [35].

The target population for the REACCTING intervention study was rural households in the KND that used biofuels (wood, animal waste, and crop residue) as their main cooking fuel source, and that contained women and young children (demographic groups typically in closest proximity to cooking activities). Data from the HDSS enabled a cluster random selection of households from the district population that met the REACCTING eligibility criteria. The social structure in this region is such that groups of related households live in connected compounds. For the purposes of the HDSS, compounds are grouped into geographic clusters. These clusters are grouped into five geographic regions: four of these are primarily rural (North, East, South, and West), while the Central region contains Navrongo town and surrounding areas. For the REACCTING sample, we first eliminated households from the Central region, and then randomly selected 25 clusters using population weighting to determine the number of clusters selected per region. Within each cluster, eight households were randomly selected from the population of households that met the study eligibility criteria, resulting in a total sample of 200 households.

The stove intervention of the REACCTING study included four different intervention arms: Group A received two Gyapa stoves, Group B received two Philips stoves, Group $C$ received one of each type of stove, and Group D served as the control for the duration of the study and received two stoves of their choice at the study's conclusion. Stove stacking (i.e., households using new cookstoves alongside traditional cooking methods) had been observed in prior studies and we had earlier observed multiple stove use by the households in the study area. Multiple stoves were thus provided to each intervention household to increase the probability that households would begin to substitute away from 
traditional stoves rather than simply adding a new stove to their cooking technology mix. Randomization into intervention groups was done at the cluster level: i.e., within each of the 25 clusters, there are 2 households in each of the 4 REACCTING intervention groups. Stove distribution for the three intervention arms (A-C) occurred in December of 2013 and January of 2014. The control group (D) received their stoves in mid-2016.

\section{P3 intervention design}

To investigate how prices, peers, and perceptions affect adoption of improved cookstoves, our study leverages the fact that the REACCTING study's free distribution of stoves to randomly selected households provides those households' peers with information about these new technologies. Building on this prior work, the P3 study offers new stoves at different price levels to groups of households with and without social ties to the households that received stoves as part of this prior study. Through these experiments, we will be able to identify the interacting feedbacks between prices and peer effects on perceptions of stoves, as well as adoption, use, and personal exposure outcomes across different groups. Our study design is targeted towards these specific research questions:

1. How are prior perceptions of the benefits of a new technology affected by the technology's price? For example, does higher price signal higher quality to target users?

2. How do prior perceptions of a new technology vary based on connections to peers that have experience with that technology? Specifically, how do peers' adoption and use histories help potential users of a technology learn about product quality?

3. How does peers' experience influence the relationship between price, on the one hand, and perceptions, technology adoption and use outcomes, on the other? Do peer effects increase or decrease the price elasticity of demand for the new technology?

4. How do perceptions of a technology change over time among households that adopt that technology initially? How do these perceptions relate to objective measures of stove performance (e.g., personal exposure to pollutants), and what is the relationship between perceptions and technology use over time?

5. How much cleaner are the improved stoves, operated by end users, than traditional stoves? What emission and pollutant exposure differences exist among the improved and traditional stoves and how does user behavior impact these outcomes?
We address these questions, which are of central interest to the public health community, using interdisciplinary methods, data collection and analysis.

\section{Stove selection}

The design of our intervention requires that we offer stoves that are similar to those offered for the REACCTING study, since we are measuring whether learning about these technologies through peers influences adoption decisions. However, our experience in the REACCTING study revealed some key challenges with the two specific stove models used in that study (the Gyapa rocket stove and Philips forced draft stove). We thus elected to use slightly different stove models for the P3 project. A review of available technologies and consultation with manufacturers led us to select the ACE1 forced draft stove as a replacement for the Philips. Similar consultations and lab testing at $\mathrm{CU}$ Boulder allowed us to narrow our rocket stove options down to two: the Greenway Jumbo and the EcoZoom Dura. A focus group discussion was conducted in September 2016 with participants similar to our target customers to compare and assess preferences for these two models. During the focus group discussion, the team demonstrated the use of these stoves to participants. Participants were then divided into groups and given the necessary ingredients/materials to use the stoves to cook a common dish (jollof rice). Participants gave positive feedback on both stoves, but expressed a slight preference for the Greenway Jumbo, which we subsequently selected for our intervention.

\section{Sample selection}

The study design is summarized in Fig. 3. For the purposes of this design, we refer to the REACCTING study sample as the R Group. Newly enrolled households that are the primary focus of the P3 study, are referred to as the S Group. Our two-phase sample selection procedure involves first selecting clusters, and then selecting households within each cluster. In the first phase, the S1 subgroup was selected to include the same clusters as the R Group households (25 clusters), while the $\mathbf{S} 2$ subgroup consists of 25 clusters randomly selected from the rural areas of the KND outside of a certain buffer distance from the R Group clusters. Given that there are more than 300 clusters in the district and only 25 were included in the R Group, social ties between S2 and R Group households are expected to be minimal (and are measured as part of our data collection).

Next, the required number of households was selected from each cluster. We used the same inclusion and exclusion criteria used to select households in the REACCTING study (i.e., rural, using biofuel, having one woman 18-55 and one child under 5). S1 group households were selected as nearest eligible neighbors of each of the 6 REACCTING intervention households in each cluster. In 


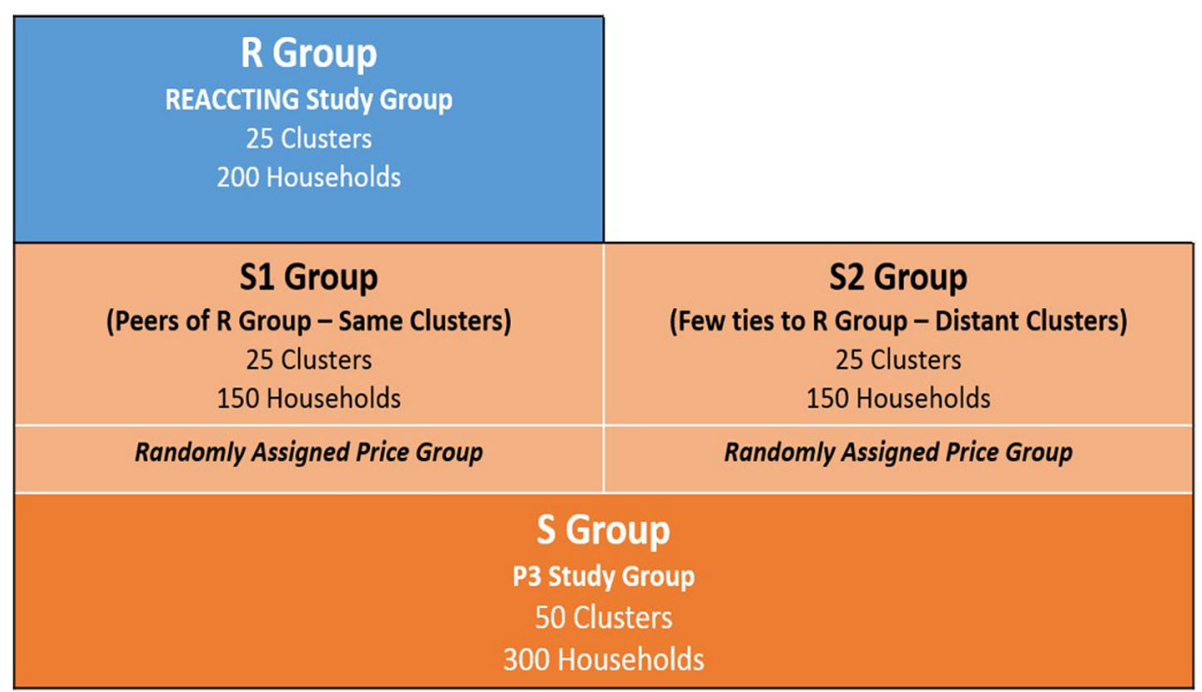

Fig. 3 Study design

the non-peer clusters, 6 seed households, each meeting the above eligibility criteria, were randomly selected, and then non-peer group households were selected as the nearest neighbors of those seed households.

By using a uniform set of selection criteria and sampling methods between the peer and non-peer groups, and given that both the R/S1 group and the S2 group clusters were randomly selected, the study design ensures that in expectation the only differences between S1 and S2 group households is the former's higher level of contact with peers that have cookstove experience, enabling us to test the impacts of peers on our outcomes of interest (perceptions and technology adoption and use).

\section{Setting stove prices}

To examine the effects of price (and the interactive effects of prices and peers) on perceptions and technology adoption, both S1 and S2 Groups were randomly subdivided into multiple price treatment groups. The price randomization is done at the cluster level - i.e., all households in a cluster are offered stoves at the same price.

In order to generate variation in stove purchasing behavior that we can use to assess impacts of prices and peers, we require information on an approximate range for households' willingness to pay (WTP) for the different stove models in the study population. Estimates of WTP come from two primary sources. First, during the REACCTING study, we measured participants WTP for improved stoves at multiple time points. During the study's baseline survey, a choice experiment was conducted to assess stated WTP for hypothetical stoves with different attributes (e.g., less smoke, faster cooking time relative to traditional stoves). These stated WTP values were quite high; for example, average WTP for stoves that produced less smoke was on the order of $200 \mathrm{GHC}$ ( USD\$50) [36].

Due to concerns that these stated WTP values may have been larger than households' true willingness and ability to pay for improved stoves in this area, we decided to collect revealed preference information on WTP during the P3 design phase. Specifically, in November of 2015 we conducted a series of five focus group discussions (FGDs) in which we conducted a 2nd price, sealed-bid auction of different stove models. Under classical economic assumptions, participants should bid their true ex ante WTP for the good [37]. The bid data from these auctions therefore provide some guidance on the range of households' WTP for different stove models. We auctioned one "mid/low-quality" stove - the Gyapa stove used in the REACCTING study - and two "high-quality" stove models - the ACE1 and the Philips. The mean bid for the higher quality stoves was $67 \%$ higher than for the Gyapa (Table 1). A quarter of participants in the higher-quality stove auctions bid at least 30 cedis, whereas only $5 \%$ of participants in the lower-quality stove auctions bid at least this amount (Fig. 4).

\section{Randomizing prices across clusters}

The experimental design for these interventions involves selecting price levels for the two stoves and distributing these prices across the peer and non-peer clusters. These price levels are set with the aim of maximizing the statistical precision of estimated economic demand for the stoves. The design procedure adopts methods from the economic discrete choice experiment literature, to select price levels which maximize the D-efficiency criterion [38] and uses prior, preliminary information on households' WTP for the stoves elicited in auctions during the FGDs. 
Table 1 Bid amounts for three types of stoves sold in auctions

\begin{tabular}{llll}
\hline Stove & $\begin{array}{l}\text { Number } \\
\text { of Bids }\end{array}$ & \multicolumn{2}{c}{ Bids (Ghanian cedis) } \\
\cline { 3 - 4 } & 31 & 13.10 & Std. Dev. \\
\hline Gyapa & 23 & 19.35 & 8.19 \\
Philips & 27 & 24.04 & 16.88 \\
ACE & & & 25.25 \\
\hline
\end{tabular}

We use a D-efficiency method, which follows the standard principle of seeking a set of experimental treatments which minimize the asymptotic covariance of the treatment effect estimates given a fixed sample size. We follow standard practice in the discrete choice econometric literature and base our D-efficiency design on a conditional logit model [39, 40], in which the probability of an experimental subject selecting stove $j$ from a choice set $t$ is:

$$
p_{j \mid t}(\beta)=\frac{\exp \beta x_{j}}{\sum_{k \in J} \exp \beta x_{k}}
$$

where $x_{j}$ is a column vector of the stove's $K$ attributes (in our application, price and the stove model) and $\beta$ are regression coefficients to be estimated. D-efficiency seeks to identify a series of choice sets $t=1, \ldots, T$ that minimize the expected asymptotic variance of maximum-likelihood estimate (MLE), $\beta_{M L E}$. The asymptotic variance of the MLE is inversely proportional to the Fischer information matrix, which in the conditional logit model with $T$ choice sets compromised of $A$ alternatives each is:

$$
\mathcal{I}(\beta \mid \mathcal{X})=\sum_{t=1}^{T} X_{t}^{\prime}\left[\operatorname{diag}\left(\boldsymbol{p}_{t}\left(\beta, X_{t}\right)\right)-\boldsymbol{p}_{t}\left(\beta, X_{t}\right)^{\prime} \boldsymbol{p}_{t}\left(\beta, X_{t}\right)\right] X_{t}
$$

where $X_{t}$ is the $K \times A$ matrix of attributes of each alternative in choice set $t, \mathcal{X}$ is the collection of these matrices over all $T$ choice sets, and $\boldsymbol{p}_{t}\left(\beta, X_{t}\right)$ is the $1 \times A$ vector of conditional logit predicted probabilities given regression estimates $\beta$ and attributes $X_{t}$. (In matrix notation, the $\operatorname{diag}(x)$ function of a vector $x$ forms a square matrix with the elements of $x$ along the diagonal and zeros everywhere else, and $X^{\prime}$ denotes the transpose of $X$.) The D-efficiency objective is to find a collection $\mathcal{X}$ of alternatives and attributes which maximize the determinant of $\mathcal{I}\left(\beta_{M L E} \mid \mathcal{X}\right)$. In practice,

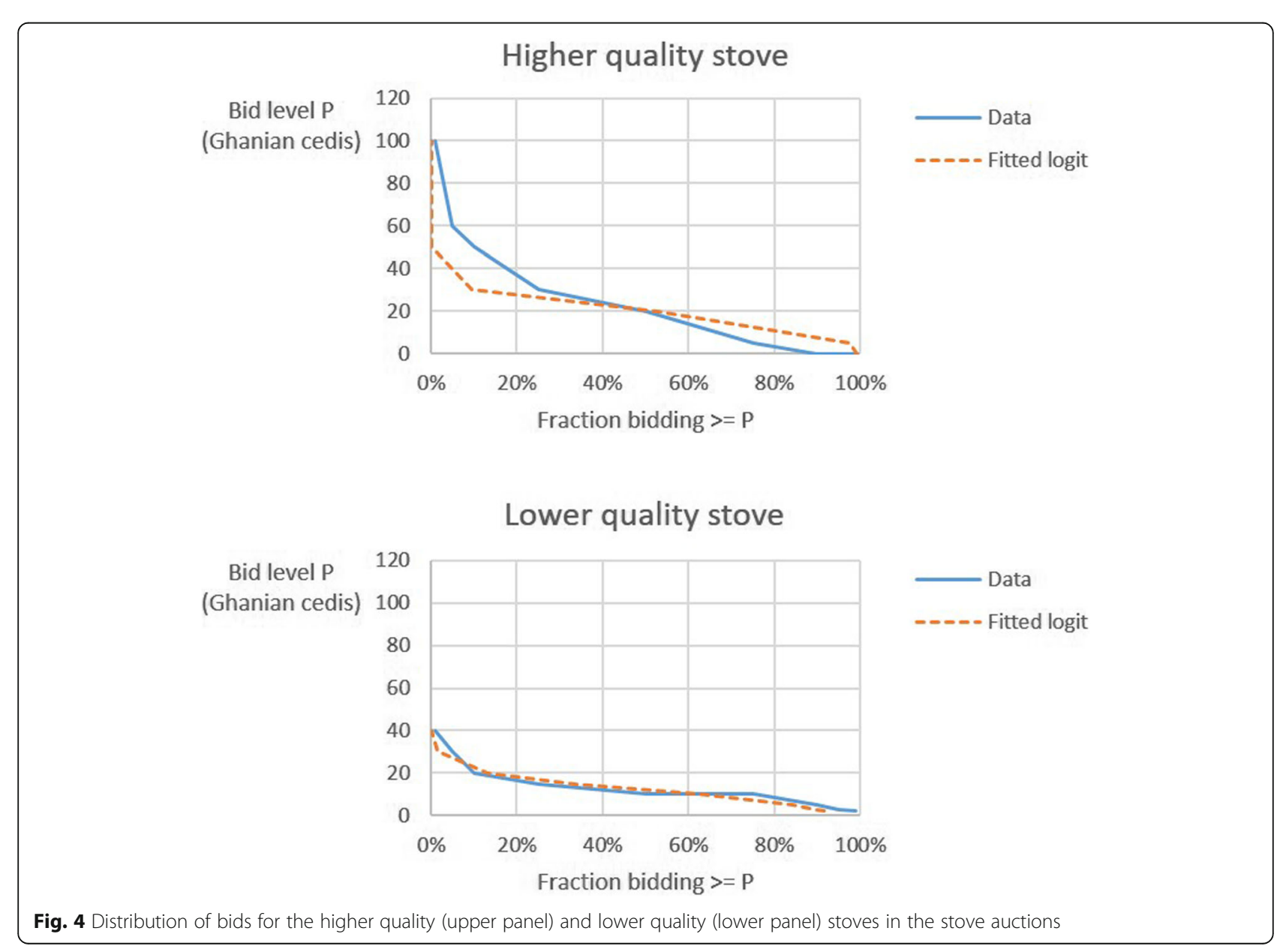


$\beta_{M L E}$ is not known a priori, and so an initial guess $\beta_{0}$ is used in experimental design.

Based on study resources, we decided that each household would be offered the option of purchasing up to two stoves consisting of any combination of the higher and/or lower quality stove models at prices randomly assigned to that household's cluster. Therefore, each choice set consisted of 6 alternatives (1-2 stoves of only one model, 1 of each model, or no stoves), and the only components of $\mathcal{X}$ that were experimentally controlled were these price levels. For logistical ease, we prespecified the possible price levels to be $0,30,60,120$ or 240 Ghanian cedis, which encompassed a range of prices from free-distribution to near $100 \%$ the cost of the stoves. Following standard practice, dominated alternatives were also eliminated from the design: in our case price configurations in which the lower-quality stove was sold at a higher price than the higher quality stove. The initial guess $\beta_{0}$ of the conditional logit regression coefficients was obtained first from logit curves fitted to the FGD auctions (Fig. 5 above). The experiment was also stratified by study subregion (North, South, East or West), and replicated in S1 and S2 clusters. After launching the sales experiment in the North, we observed higher than expected stove demand, based on the FGD auctions; we therefore redesigned the price treatments again with the D-efficiency method for the remaining three regions based on this higher observed demand.

\section{Assessment of intervention impacts}

In order to measure the impacts of the intervention, we collect data on multiple covariates and outcomes using surveys and other monitoring instruments. The variables that will be measured are summarized in Table 2.

\section{Baseline household survey}

For all 300 household participants, we conducted a comprehensive baseline survey between Dec 2016 and Feb 2017. This survey measured household composition and demographics, attitudes and priorities, cooking behaviors (including type(s) of stoves used, fuel use, foods cooked, who cooks within household), knowledge and perceptions of issues related to cooking practices, demand for new stoves, and self-reported health measures. In each household, the primary cook (typically female, aged 1855 years old) served as the main survey respondent. In households where another male household member makes financial decisions, we also conducted a secondary survey with this individual. All baseline and follow up surveys are conducted using electronic tablets and the Open Data Kit (ODK) software.

\section{Perceptions survey}

After stove orders were made, but before the recipients received their new stoves, we conducted a short follow up ODK survey with all 300 households to measure their perceptions of the different types of stoves (Jun-Aug 2017). Since our central research questions involve the roles of both prices and peers in shaping stove perceptions, these surveys provide important data on how participants perceive the different stoves and what benefits they expect to derive from them a priori.

\section{Endline survey}

An endline survey will be conducted with all households in Aug-Oct 2018. This survey will collect information on the same topics measured in the baseline and perceptions surveys. A focus will be on measuring use of both traditional and improved stoves, satisfaction with stoves' performance, and perceptions of stoves' impact on household air quality (to be compared with objectively measured air quality and exposure data).

\section{Stove orders, payments, and refusals}

The intervention is being implemented by a local environmental NGO, the Organization for Indigenous Initiatives and Sustainability (ORGIIS). Between March and May of 2017, ORGIIS and NHRC staff held a series of cluster-level meetings (6 households per cluster) during which they demonstrated the two types of stoves and explained their benefits, and then provided participants the choice to purchase 0,1 , or 2 stoves (total) of either type at the cluster-randomized price levels. Stoves were then ordered from manufacturers and imported; stoves arrived in Navrongo in August, and were distributed to participants in October of 2017. ORGIIS staff will collect payments for stoves over a six month period, with first payment due at the time of delivery. (This payment arrangement was explained during the stove offer meetings, so households were able to make their purchasing choices with this information.) ORGIIS staff are also trained in stove maintenance and repairs, and are available to troubleshoot any problems that households face in using their stoves. In addition, follow-up visits are being conducted periodically to encourage households to use their stoves and assess any challenges users are facing.

Detailed data on stove orders and payments are being collected and shared with the research team. This includes any instances in which households who initially ordered stoves decide not to follow through with their purchases at the time of delivery, or fail to make all necessary payments within a six month period (in which case stoves will be recovered by ORGIIS, and any payments made by the household will be returned). 


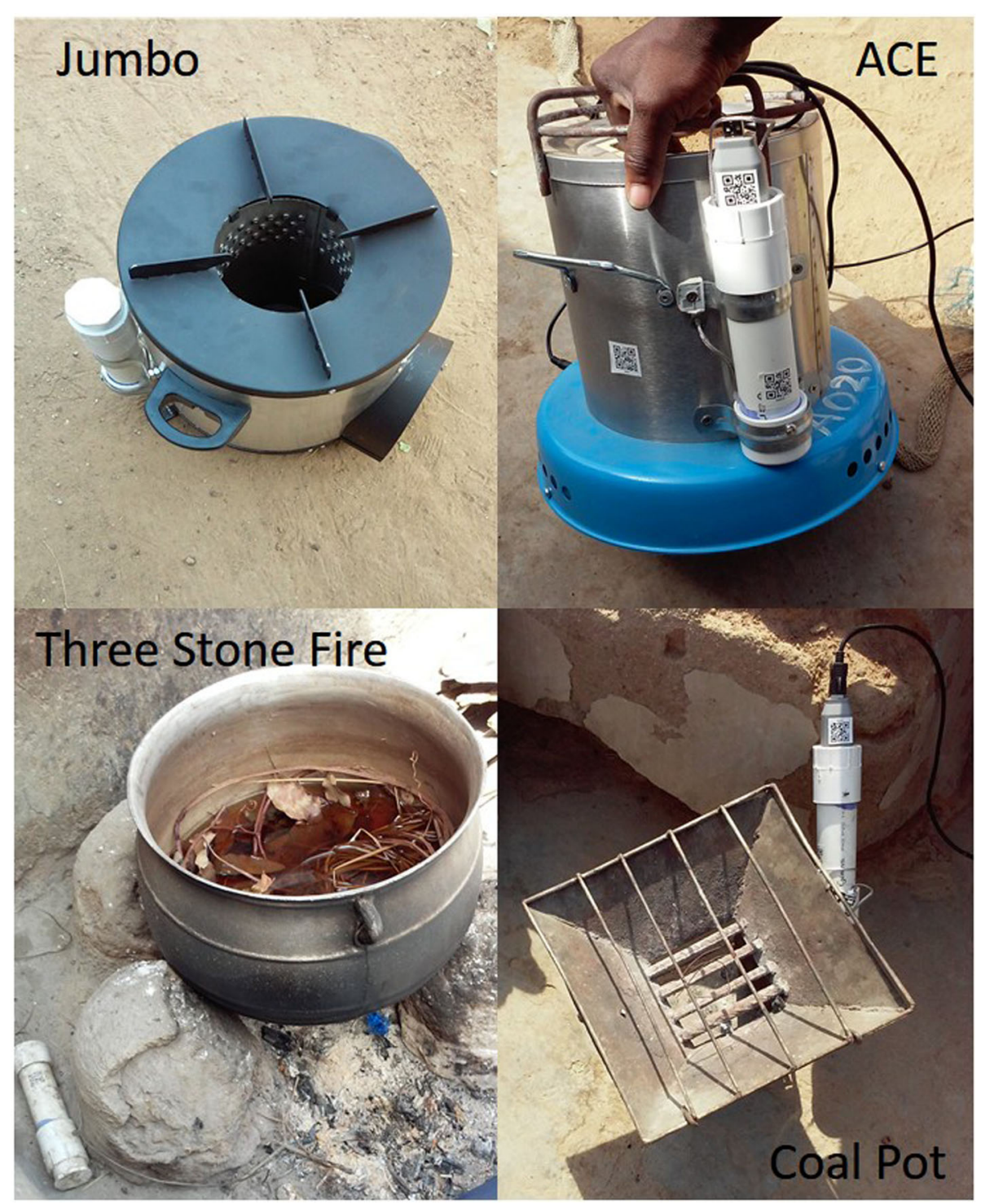

Fig. 5 Placement of stove use monitors (SUMs) on improved stoves (Jumbo and ACE) and traditional stoves (Three Stone Fire and Coal Pot). Images source: study authors

\section{Stove use monitors}

Out of the 300 household participants, a subset of about 50 households will have their stove use monitored continuously throughout the follow up period using electronic Stove Use Monitors (SUMs). These households have been selected to represent variation in bid outcomes (number and types of stoves chosen) as well as price levels and peer groups.

The SUMs units we have developed for this project consist of thermocouple data loggers (Thermocouple Temperature Data Logger SSN-61, Wellzion), Type K thermocouples (1 M K Screw Thermocouple and $2 \mathrm{M}$ Customized K Thermocouple, Wellzion), and PVC enclosures that protect the units from water and heat exposure. The total unit cost is $\sim$ USD $\$ 25$. The SUMs have a measurement range of approximately $-270{ }^{\circ} \mathrm{C}$ to $1200{ }^{\circ} \mathrm{C}$, a substantially larger range than devices such as the iButton or Labjack Digit SUMs that have been frequently used in previous cookstove studies [41] and operate from about $-40{ }^{\circ} \mathrm{C}$ to $85{ }^{\circ} \mathrm{C}$. The higher upper limit operating temperature allows us to place these SUMs as close to the hottest portion of the cookstove as desired without concern of overheating, resulting in clearer designations between heating due to the sun or ambient temperature rises and actual cooking events.

In each of the 50 selected SUMs households, all stoves within the household (improved and traditional) will be equipped with SUMs. Different types of stoves require slightly different SUMs placement to optimize data quality and cooking event detection (see Fig. 5). For the 
Table 2 Summary of measurements to be included in study

\begin{tabular}{|c|c|c|c|c|}
\hline Variable & Description & Data Source & Groups Measured & $\begin{array}{l}\text { Timing of } \\
\text { Measurements }\end{array}$ \\
\hline Social Networks & Linkages among and between S Group and R Group households & Surveys & $\begin{array}{l}\text { All households } \\
\text { (R and S Groups) }\end{array}$ & Baseline, Endline \\
\hline \multirow[t]{2}{*}{$\begin{array}{l}\text { Stove } \\
\text { Perceptions }\end{array}$} & $\begin{array}{l}\text { Likert-scale and subjective expectation questions measuring } \\
\text { perceptions of stove quality / performance for both stove types } \\
\text { along multiple dimensions: smoke, fuel use, cooking time, } \\
\text { durability, ease of use, suitability for cooking common dishes. }\end{array}$ & Surveys & $\begin{array}{l}\text { All households } \\
\text { (R and S Groups) }\end{array}$ & $\begin{array}{l}\text { Baseline, } \\
\text { Endline }\end{array}$ \\
\hline & Stated willingness to pay / accept for stove types & Surveys & $\begin{array}{l}\text { Already measured for } \\
\text { R Groups pre- } \\
\text { intervention; } \\
\text { Measurements added } \\
\text { for S Groups }\end{array}$ & Baseline, Endline \\
\hline Stove Choice & Number $(0,1$, or 2$)$ and type(s) of stoves selected and purchased & $\begin{array}{l}\text { Stove orders and } \\
\text { delivery / } \\
\text { payment }\end{array}$ & $\begin{array}{l}\text { S Groups } \\
\text { R Control Group }\end{array}$ & $\begin{array}{l}\text { Baseline and } \\
\text { Stove Delivery }\end{array}$ \\
\hline \multirow[t]{2}{*}{ Stove Use } & $\begin{array}{l}\text { Reported use of all stoves (traditional and improved) in all } \\
\text { households on day and week prior to surveys }\end{array}$ & Surveys & $\begin{array}{l}\text { All households } \\
\text { (R and S Groups) }\end{array}$ & Baseline, Endline \\
\hline & Electronic monitoring of stove temperature & $\begin{array}{l}\text { Stove Use } \\
\text { Monitors (SUMs) }\end{array}$ & $\begin{array}{l}\text { Subset of stoves \& } \\
\text { households across all } \\
\text { groups }\end{array}$ & Continuous \\
\hline \multirow[t]{3}{*}{ Stove Impacts } & $\begin{array}{l}\text { Kitchen concentrations of and personal exposure to carbon } \\
\text { monoxide }(\mathrm{CO}) \text { and particular matter }\left(\mathrm{PM}_{2.5}\right) \text { among study } \\
\text { participants }\end{array}$ & $\begin{array}{l}\mathrm{CO} \text { and PM } \\
\text { monitors }\end{array}$ & $\begin{array}{l}\text { Same households as } \\
\text { SUMs (above) }\end{array}$ & $\begin{array}{l}\text { 48-h } \\
\text { measurements } \\
\text { every } 3 \text { months }\end{array}$ \\
\hline & Self-reported health symptoms & Surveys & All households & $\begin{array}{l}\text { Baseline, } \\
\text { Endline }\end{array}$ \\
\hline & $\begin{array}{l}\text { Cost of illness: direct and indirect costs of treating any reported } \\
\text { illnesses }\end{array}$ & Surveys & All households & $\begin{array}{l}\text { Baseline, } \\
\text { Endline }\end{array}$ \\
\hline $\begin{array}{l}\text { Household } \\
\text { characteristics }\end{array}$ & $\begin{array}{l}\text { Household location, size and demographics, baseline cooking fuel, } \\
\text { socioeconomics }\end{array}$ & HDSS & $\begin{array}{l}\text { All households in } \\
\text { district }\end{array}$ & Every $1-2$ years \\
\hline $\begin{array}{l}\text { Additional } \\
\text { socioeconomic } \\
\text { variables }\end{array}$ & $\begin{array}{l}\text { Education, occupation of respondent and household heads } \\
\text { Expenditure inventories } \\
\text { Agricultural practices }\end{array}$ & Surveys & $\begin{array}{l}\text { All households in } \\
\text { study }\end{array}$ & Baseline, Endline \\
\hline $\begin{array}{l}\text { School } \\
\text { attendance }\end{array}$ & Number of absences for school children enrolled in study & School records & $\begin{array}{l}\text { All households in } \\
\text { study }\end{array}$ & Yearly \\
\hline
\end{tabular}

improved stoves, SUMs units are secured to the side using metal tube brackets screwed into the stove, and the thermocouple probe is screwed directly into the tapped metal side of the stove. Placement for traditional stoves (charcoal stoves and three stone fires) is somewhat more complicated given variation in stove designs throughout the study area. Examples of placements for each of these stoves are shown in Fig. 5. SUMs measurements of three stone fires have proven particularly challenging in previous work [42]. Our protocol for these stoves involves placing the probe within six inches of the center of the fire, securing the probe and wire with multiple 6" long ground staples, and extending the PVC enclosure away from the stove and covering it with stones or other objects to stabilize and secure the unit. Pre-testing was completed to ensure that the probe type and placement on each stove type yielded a large enough temperature increase when the stove was 'on' to recognize a cooking event.

SUMs units are set to log a temperature reading every five minutes. Using this logging interval, SUMs have enough memory to log for 111 days, so team members visit these households to download data at least once every three months. Units are equipped with a watertight screw-top adapter that allows the field team to remove the SUM and download data in the field. Each SUM and stove is labeled with a QR code sticker, which allows us to keep track of which SUM corresponds to which stove as well as which stoves are in each household. At each data download visit, an electronic survey (ODK) is completed to record reported stove use, any issues with the stove, stove location, fuel use, and any problems with the SUMs.

\section{Personal exposure and household air quality}

Expanding on previous personal exposure and household air quality assessments completed in the KND [43, 44], this study aims to further quantify the effects of new stove technologies on personal exposure and household air quality and explore relationships between the two. Personal exposure and household air quality will be measured 
in a subset $(n=40)$ of households receiving SUMs. Biweekly, eight households are visited for exposure sampling: four from Monday to Wednesday and another four from Wednesday to Friday. This sampling allows 2-3 repeat visits to each household over the follow up period to explore within-household variation.

Personal exposure to carbon monoxide $(\mathrm{CO})$ and particulate matter less than $2.5 \mu \mathrm{m}$ in diameter $\left(\mathrm{PM}_{2.5}\right)$ are measured using near real-time CO loggers (EL-USB-CO $\sim$ USD\$125, Lascar Electronics) and light scattering $\mathrm{PM}_{2.5}$ sensors (HAPEx Nano $\sim$ USD $\$ 120$, Climate Solutions Consulting). Each device is set to store data with one-minute time resolution although longer sampling intervals are optional. The HAPEx averages three 20-s samples for each minute reading. Monitors are affixed to lanyards or waist packs and worn by the primary cook and, if present, children under the age of 5 for a duration of $48 \mathrm{~h}$ to account for day-to-day variability. Young children are given custom t-shirts with pockets sewn on the lapel to hold the instruments.

The Lascars and HAPEx loggers represent some of the strongest exposure monitoring tool candidates balancing price, size and data quality. Lascar loggers are one of the most prevalent $\mathrm{CO}$ monitoring tools in personal exposure assessment due to the ease of use and general reliability. They have been found to be reasonably accurate and precise yet require calibration before use and continued characterization over time due to sensitivity changes and response time lags, due in part to sensor fouling [44]. The Lascars house electrochemical sensors which are calibrated in the lab using a normalization technique and at the field site every 2 months using zero air and span gases. The HAPEx Nano (Climate Solutions Cons.) instrument is a proxy for $\mathrm{PM}_{2.5}$ and incorporates the Sharp GP2Y sensor. The Nano has been found to be one the highest performing low-cost portable sensors for exposure assessment during lab tests and, more importantly, in field validation [45]. The Nanos are zeroed once a week in a clean chamber and rotate through a 48-h collocation with a set of pump and filters at a focus household (described below). These cumulative $\mathrm{PM}_{2.5}$ filter measurements act as a reference with which to normalize the Nano readings. The HAPEx Nano also employs an accelerometer to measure compliance.

Personal exposure has been found to be highly dependent on a participant's time-activity [46-50]. In order to gain a better understanding of the exposure incurred from each stove type, proximity monitors are employed at each deployment household in the primary and secondary kitchen areas. Using a network of Bluetooth Low Energy (BLE) emitters (beacons worn by participants, Roximity) and receivers (Android cell phones positioned next to the cookstoves), distance to cooking areas can be estimated using registered signal strengths indications (RSSI) akin to the method conducted in REACCTING and similar to other time-activity monitoring approaches [51]. Coupled with SUM information and proximity data, exposure to $\mathrm{CO}$ and $\mathrm{PM}_{2.5}$ can be apportioned to various activities and stove types. Moreover, monitoring a subset of participant's location using a GPS-enabled watch (Suunto Ambit3 Peak) offers participant time-activity information for validation of measured proximity categories (e.g., at home, away from home) and the ability to indicate exposure incurred outside the household, a potentially large fraction of total exposure [43, 44, 52]. Proximity information will also be integrated with SUM data to explore how cooking behavior (e.g., time tending fire) changes based on stove.

During each deployment period, one of the four households (rotating across the groups) is selected to participate in a series of supplementary measurements conducted in the primary kitchen. This focus household receives a G-Pod (mobilesensingtechnology.com) which is positioned one meter away from and one meter above the most used cookstove [33]. The G-Pod is a custom air quality sensor platform which measures $\mathrm{CO}, \mathrm{CO}_{2}$, temperature, humidity and pressure at sub-minute intervals and is integrated with two HAPEx Nanos for measurements of kitchen level $\mathrm{PM}_{2.5}$ (Fig. 6). Lastly, the G-Pod is outfitted with two pumps and filter sampling trains to measure $\mathrm{PM}_{2.5}$ mass and carbonaceous $\mathrm{PM}_{2.5}$. Train one is composed of a cyclone inlet (URG2000-30EQ) followed by a filter holder (URG-2000-30FG) containing a $47 \mathrm{~mm}$ PTFE filter (Teflo FPTPMP247) and then a pump (SKC PCXR8) adapted to pull a constant volume $(3.0 \pm 0.02 \mathrm{Lpm})$ of air for $48 \mathrm{~h}$. Train two incorporates an impactor (URG-2000-30PASS-1), then a filter holder (URG-2000-25F-2-2.5) containing a $25 \mathrm{~mm}$ quartz fiber filter (Pall Tissuquartz 7200), and subsequently a pump (SKC AirLite) adapted to pull a constant volume $(2.0 \pm 0.02 \mathrm{Lpm})$ of air for $48 \mathrm{~h}$. The G-Pod and filter sampling trains are powered by a $12-\mathrm{V}$ car battery and last a full week without recharging. The pumps are both housed in a protective case with reflective surfaces to reduce overheating (see Fig. 6). The duration of the pump sampling is recorded by one pump (SKC PCXR8) and a custom PCB located within the pump enclosure acts as a redundant measure of total elapsed time.

\section{Emissions measurements}

Building on the REACCTING work, the research team has been collecting a set of emissions samples from multiple different types of sources in the study area. These samples help to characterize emissions from other sources, beyond residential cooking, that contribute to ambient air pollution and personal exposures. These include samples from the following sources: commercial cooking, traffic, kerosene lighting, trash burning, charcoal making, bush burning, 


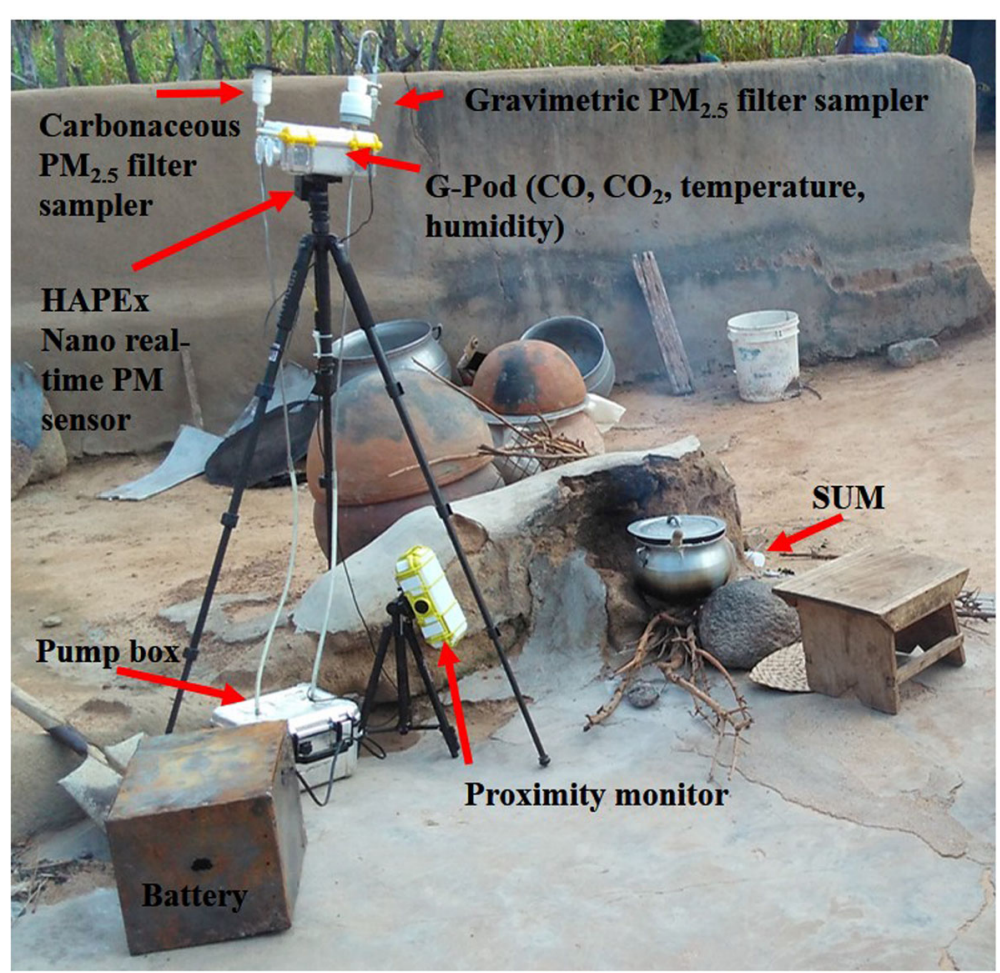

Fig. 6 Monitoring equipment arrangement at an outdoor cooking area with a three stone fire. Images source: study authors

diesel generators, and pito (local fermented beverage) brewing. These will continue with the goal of informing the pollutant exposure apportionment and cooking behavior study activities.

\section{Analysis and integration}

To analyze stove purchase outcomes, we will estimate models of stove demand using discrete choice econometric methods [53], based on the experimental design described above. This analysis will be used first to statistically test the basic hypothesis that higher stove prices lead to lower demand for the stoves, all else equal (i.e. the 'Law of Demand' in economics). We also hypothesize that the higher-quality stoves will be in higher demand and that more of one or both stoves are weakly preferred, ceteris paribus.

After testing these basic hypotheses, we will then examine between-cluster heterogeneity in stove demand to investigate a primary research question of this study: whether households in the S1 group, previously exposed to peers with improved cookstoves, have statistically different demand for stoves compared to the S2 group. Formally, this will be tested first by jointly estimating stove demand using conditional logit and other discrete choice models for both groups. By interacting an indicator for S1 and S2 group assignment with stove model and price coefficients in the regression analysis, we will examine whether being in the peer group affects demand by shifting it up or down, or by changing price elasticity (i.e. making the demand curve flatter or steeper). While assignment to S1 and S2 groups is random, by virtue of the previous REACCTING study, we also include household characteristics collected from surveys in these demand models, to improve statistical efficiency of the analysis. We will also estimate mixed logit and latent class discrete choice models, to test whether unobserved preference heterogeneity is a statistically significant factor driving stove demand, and whether this preference heterogeneity is altered by S1/S2 group assignment.

Stove demand models will be estimated using both initial stove orders and completed stove purchases, with the understanding that some households who order stoves initially may ultimately be unwilling or unable to complete their purchases. If defaults are common, we will analyze factors associated with this outcome, including stove price, peer contact, and socioeconomic status, among other variables. In addition, we will conduct similar analyses to assess whether prices, peers, and/or perceptions affect stove use (measured by surveys and SUMs).

From an air quality perspective, there are three main objectives to the analysis: (1) apportion $\mathrm{CO}$ and $\mathrm{PM}_{2.5}$ exposure to various cooking and non-cooking related activities at and away from the household (see Fig. 7), (2) estimate what effects the improved cookstoves have on $\mathrm{CO}$ and $\mathrm{PM}_{2.5}$ exposure across groups in addition to 
comparing within- and between-household variation, and (3) investigate relationships between mixing ratios of various combustion species $\left(\mathrm{CO} / \mathrm{CO}_{2}, \mathrm{CO} / \mathrm{PM}_{2.5}\right)$ at the personal and microenvironmental levels to inform models estimating cumulative exposure [see 43]. These three objectives depend on contemporaneously measured stove usage, time-activity and exposure data at the various study households.

To briefly illustrate the synthesis of these data, Fig. 8 depicts preliminary data from a 48 -h deployment timeseries indicating measurements of a) participant proximity to the nearest cooking area and GPS location classification (at home or away, green band) with b) PM and $\mathrm{CO}$ exposure and c) stove usage for all five cookstoves at this household (normalized to individual-stove maximum temperature). The colored bands indicate a stove usage event and extend vertically to highlight the concurrently measured user proximity and exposure. Exposure incurred at moments in which participants are near a stove, and that stove is in use (see blue band on left) can be apportioned appropriately. Contrast this with the interval marked by the yellow band representing a clear three stone fire event, however, the proximity data indicates the participant is not near the stove and has minimal incurred exposure.

To advance the analysis, we plan to perform a comprehensive uncertainty assessment of each data stream including a rigorous in-field photo validation of stove use and proximity, a task seldom pursued in large scale interventions. We also aim to improve the explanation of variation between mean HAPEx Nano measurements and cumulative gravimetric $\mathrm{PM}_{2.5}$ measurements with the inclusion of temperature, humidity, pressure, kitchen level $\mathrm{CO}$ and $\mathrm{CO}_{2}$ concentrations as well as the sample chemical composition (e.g. elemental carbon, organic carbon) from speciated $\mathrm{PM}_{2.5}$.

A final type of integration involves using both survey and measurement data to examine relationships among stove perceptions, stove use, and stove performance. For example, we will assess whether households that perceive stoves to be cleaner actually use their stoves more and/or experience reduced exposure to pollutants.

Results will be disseminated through peer reviewed publications and scientific conferences, as well as through community meetings with study participants.

\section{Discussion}

The P3 project seeks to provide a much needed integration of approaches to understanding the drivers and impacts of public health-related technology adoption. In many prior cookstove studies, epidemiologists have sought to measure the health effects of cleaner cooking devices, only to be confronted with the problem of "imperfect compliance": that is, households' failure to switch to exclusive use of the cleaner stoves [e.g., 54]. This confounder, from the perspective of epidemiologists, is the main research question for social scientists: how and why do people decide to adopt and use a new technology? To fully understand the potential real-world public health effects of stoves and similar technologies, an interdisciplinary approach that embeds rigorous social science methods is needed.

The P3 study is uniquely positioned to address a policy relevant set of research questions in the context of public health technology adoption. Despite widespread acknowledgement that prices, peers, and perceptions are key drivers of households' decisions to adopt new technologies and behaviors, rigorous study designs testing

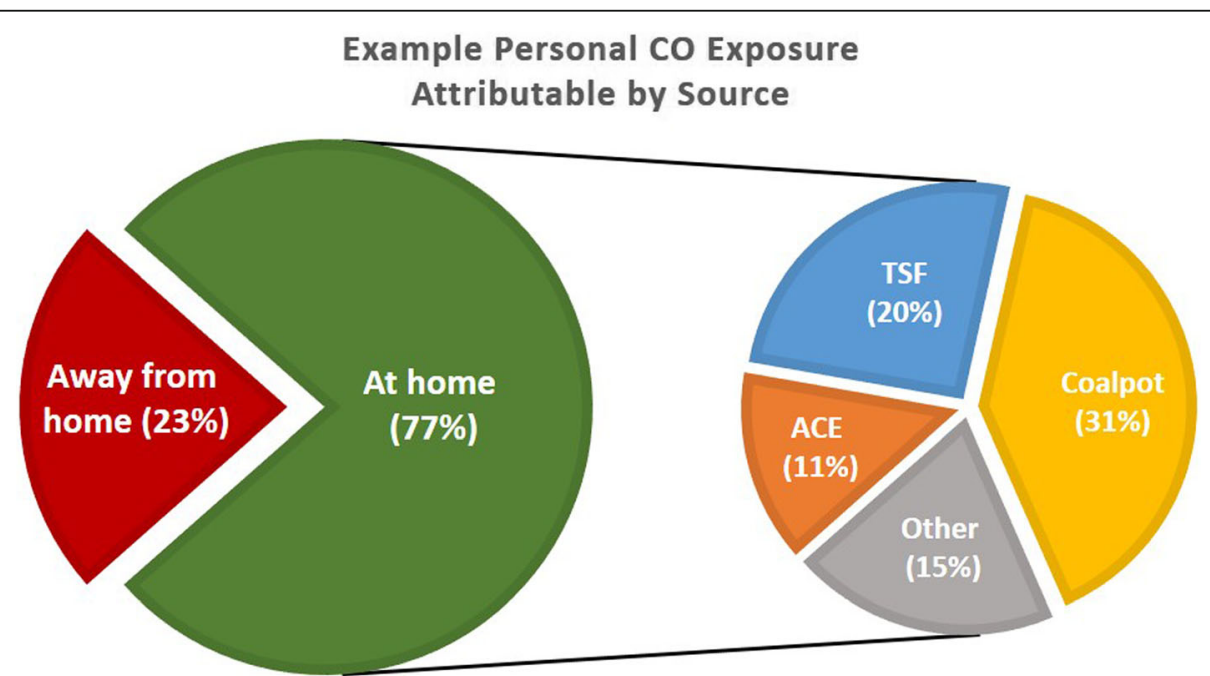

Fig. 7 Example cumulative CO exposure (pie) with source contributions (slices) identified 


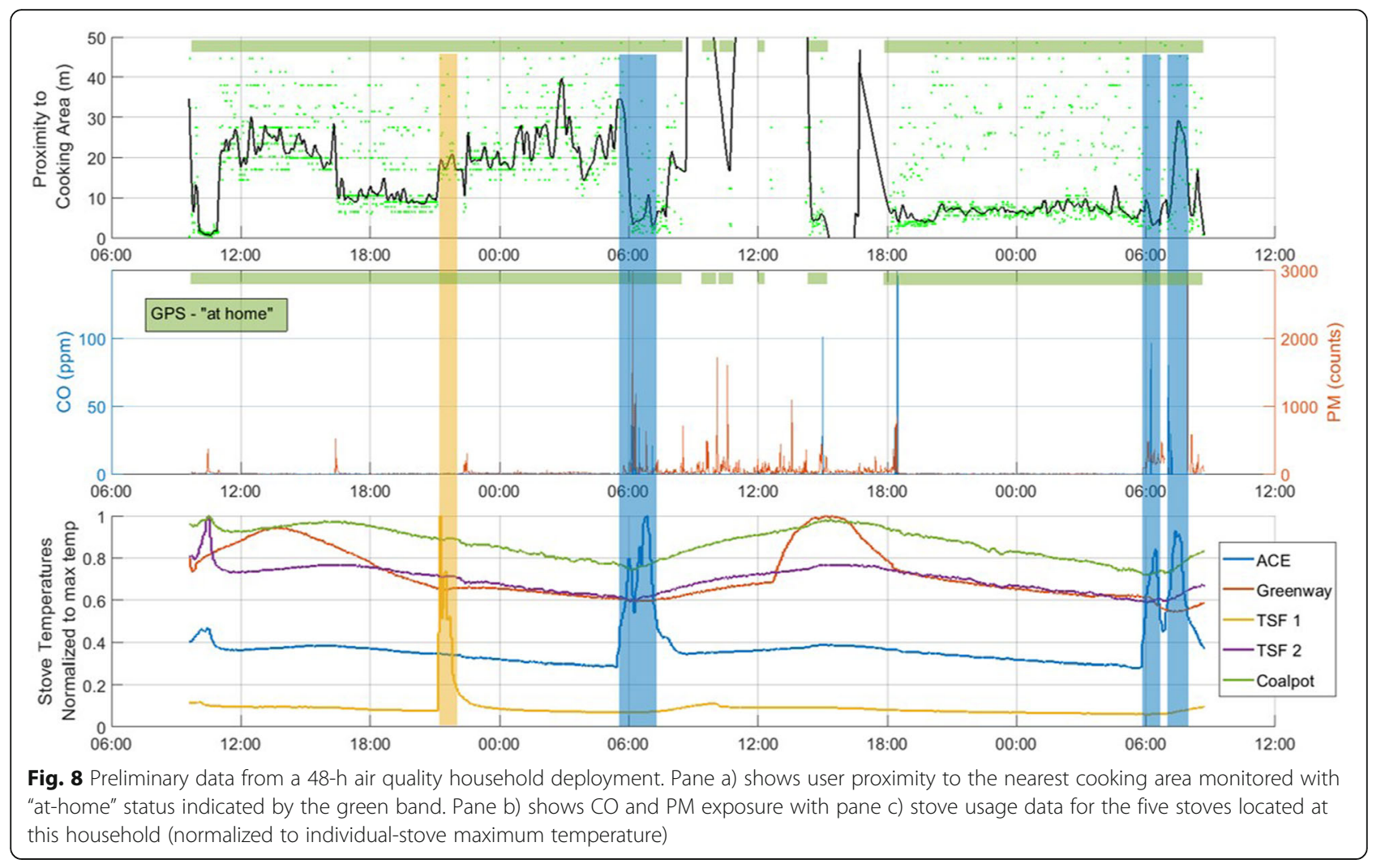

the separate and interacting effects of these factors have been elusive. By taking advantage of the randomized introduction of free stoves in the REACCTING project, we aim to fill this gap.

Our project integrates state-of-the-art social science and exposure analysis methods. Our experimental methods are rooted in economic program evaluation approaches, and incorporate stated and revealed preference methods to inform our price levels within the experiment. Notably, our inclusion of survey measures capturing users' perceptions of stoves over time will allow us to build better theoretical models of the adoption process by clarifying mechanisms linking prices and peer effects to adoption outcomes. In other words, we hope to shed light on why prices and peers shape technology choice, with implications for policy design.

Simultaneously, our exposure measurement approaches enable a more complete assessment of the linkages between stove use, emissions and exposure outcomes. The additional information offered from time-activity measurements (proximity and GPS) in concert with stove usage data enables us to apportion exposure to various at-home sources (e.g. stoves, kerosene lamps, trash burning etc.) while allowing us to identify exposure incurred outside of the home. Breaking the cumulative exposure "pie" into "slices" of source-identified contributions will enable us to disentangle cooking-related exposures, facilitating direct comparisons across stove groups and individual stove (and fuel) types. Likewise, we are well poised to explore how cooking behavior (e.g. cooking duration, proximity/tending to stove) may be affected by new stove technology adoption.

The integration of these approaches in the P3 project allow us to examine how and why technology adoption occurs and how these processes influence exposures, with key implications for public health policy and practice.

\section{Additional file}

Additional file 1: Informed Consent statement for the P3 project. (PDF $667 \mathrm{~kb}$ )

\section{Abbreviations}

CO: Carbon Monoxide; FGD: Focus Group Discussion; HAP: Household Air Pollution; HDSS: Health and Demographic Surveillance Survey; KND: KassenaNankana Districts; NHRC: Navrongo Health Research Centre; ODK: Open Data Kit; ORGIIS: Organisation for Indigenous Initiatives and Sustainability Ghana; P3: Prices, Peers, and Perceptions; PM $_{2.5}$ : Particulate Matter less than $2.5 \mu \mathrm{m}$ in diameter; REACCTING: Research on Emissions, Air quality, Climate, and Cooking Technologies in Northern Ghana; RESPIRE: Randomized Exposure Study of Pollution Indoors and Respiratory Effects; SUM: Stove Use Monitor; WTP: Willingness to Pay

\section{Acknowledgements}

We would like to acknowledge the invaluable data collection work of Sebastian Achiabase, Michael Agula, Vincent Aweduna, Godfred Kwose, and Moses Tivura. We are also grateful for the assistance of Lee Parton in the GISbased sample selection process, and to Ricardo Piedrahita for his input on 
the stove use and exposure monitoring methods. Finally, this work is made possible due to the support of all of the P3 friends, family, spouses, and children, at least four of whom were born during the design and implementation of this project (Alexandra Dickinson, Maya Dalaba, Tate DeMeester Brown, and Leroy Omar Alirigia).

\section{Ethical approval and consent to participate}

The study protocol was reviewed and approved by the Institutional Review Boards of the Navrongo Health Research Centre (NHRCIRB207) and the University of Colorado Boulder (15-0359). Given that the study poses minimal risks, informed consent is obtained orally (rather than in writing) from all study participants prior to any data collection (see Additional file 1).

\section{Funding}

This study is funded through the United States National Science Foundation's Economics program (SES 1528811) and a gift from the Rathmann Family Foundation. The funders have no role in the study design.

\section{Availability of data and materials}

Following publication of main results, deidentified household-level data will be open access with registration and a statement of interest.

\section{Authors' contributions}

$\mathrm{KD}$ is the study's principal investigator, and led the design of the project as well as the preparation of the manuscript. MD is a co-principal investigator and the project coordinator; he contributed to the study design and manuscript preparation. ZB is a co-principal investigator who led the design of the price experiment and collaborated on all aspects of the study design and manuscript preparation. RA was the project's lead research officer and is currently a graduate student research assistant; he contributed to the study design, led baseline data collection and intervention implementation, and reviewed the manuscript. EC is the team's senior field engineer; he designed and directed exposure measurement and analysis activities, and contributed to writing the manuscript. EM is a research assistant on the project who led stove testing and stove use monitoring activities, and contributed to writing the manuscript. MaA is a research assistant who has conducted stove use, emissions, and exposure measurements in the field. DA is the current lead research officer who oversees all facets of data collection; he reviewed the manuscript. MoA is a research assistant who contributed to the study design and assisted with the stove auctions. EK was the project coordinator for the REACCTING project and contributes to the implementation of the P3 project. JA directs the non-governmental organization that is implementing the intervention (ORGIIS), and contributed to the project's design. CAA, JBA, and BG work on all facets of intervention implementation and oversight. ARO is the NHRC director and project co-Pl; he facilitated the design and implementation of the project, and reviewed the manuscript. $\mathrm{MH}$ is a co-principal investigator who led the REACCTING study, collaborated on the design of the P3 project, and oversees all monitoring activities. All authors have read and approved the final version of this manuscript.

\section{Consent for publication}

Not applicable.

\section{Competing interests}

The authors declare that they have no competing interests.

\section{Publisher's Note}

Springer Nature remains neutral with regard to jurisdictional claims in published maps and institutional affiliations.

\section{Author details}

${ }^{1}$ Colorado School of Public Health, University of Colorado Anschutz Medical Campus, 13001 E 17th PI, Aurora, CO 80045, USA. Navrongo Health Research Centre, Behind Navrongo War Memorial Hospital, Navrongo, Ghana. ${ }^{3}$ North Carolina State University, Campus Box 8109, 2801 Founders Drive, Raleigh, NC 27695, USA. ${ }^{4}$ University of Colorado Boulder, College of Engineering and Applied Science, 1111 Engineering Drive, 422 UCB, Boulder, CO 80309-0422, USA. ${ }^{5}$ Organisation for Indigenous Initiatives and Sustainability Ghana, Post Office Box 1, Page, U.E, Navrongo, Ghana.
Received: 9 August 2018 Accepted: 12 October 2018

Published online: 29 October 2018

\section{References}

1. Cohen J, Dupas P. Free distribution or cost-sharing? Evidence from a randomized malaria prevention experiment*. Q J Econ. 2010;125(1):1.

2. Pattanayak SK, Blitstein J, Yang JC, Patil SR, Jones KM, Poulos C, Dickinson $\mathrm{KL}$. Evaluating information and communication strategies to promote latrine use and improve child health: design and baseline findings from a community randomized trial in Bhadrak, Orissa. Research Triangle Park, North Carolina: RTI Working Paper; 2006

3. Kremer M, Miguel E. The illusion of sustainability. Q J Econ. 2007; 122(3):1007-65.

4. Ali MM, Cleland J, Shah $\mathrm{H}$. Condom use within marriage: a neglected HIV intervention. Bull World Health Organ. 2004;82(3):180-6.

5. Pattanayak SK, Yang J-C, Dickinson KL, Poulos C, Patil SR, Mallick R, Blitstein J, Praharaj P. Shame or subsidy revisted: randomized evaluation of social mobilization for sanitation in Orissa, India. Bull World Health Organ. 2009; 87(8):580-7

6. Ashraf N, Jack BK, Kamenica E. Information and subsidies: complements or substitutes? J Econ Behav Organ. 2013;88:133-9.

7. Dickinson K, Pattanayak SK. Open sky latrines: do social interactions influence decisions to use toilets? Madison, WI: University of Wisconsin; 2008

8. Conley T, Udry C. Learning about a new technology: pineapple in Ghana. Am Econ Rev. 2010;100(1):35-69.

9. Miller G, Mobarak AM: Learning about new technologies through opinion leaders and social networks: experimental evidence on non-traditional stoves in rural Bangladesh. In: Poverty Action; 2013.

10. Smith KR. Biofuels, air pollution, and health: a global review. New York, NY: Plenum Press; 1987

11. Smith KR, Mehta S, Maeusezahl-Feuz M. Indoor air pollution from household use of solid fuels. Comparative quantification of health risks: global and regional burden of disease attributable to selected major risk factors. 2004;2:1435-93.

12. Ezzati M, Kammen DM. Indoor air pollution from biomass combustion and acute respiratory infections in Kenya: an exposure-response study. Lancet. 2001;358(9282):619-24

13. Lim SS, Vos T, Flaxman AD, Danaei G, Shibuya K, Adair-Rohani H, AlMazroa MA, Amann M, Anderson HR, Andrews KG, et al. A comparative risk assessment of burden of disease and injury attributable to 67 risk factors and risk factor clusters in 21 regions, 1990-2010: a systematic analysis for the global burden of disease study 2010. Lancet. 2012;380(9859):2224-60.

14. Bond TC, Streets DG, Yarber KF, Nelson SM, Woo JH, Klimont Z: A technology-based global inventory of black and organic carbon emissions from combustion. J Geophys Res: Atmospheres (1984-2012) 2004, 109(D14).

15. Blackden CM, Wodon Q: Gender, time use, and poverty in sub-Saharan Africa, vol. 73: World Bank publications; 2006.

16. Hanna R, Duflo E, Greenstone M: Up in smoke: the influence of household behavior on the long-run impact of improved cooking stoves. In.: National Bureau of Economic Research; 2012.

17. Smith KR, Bruce N, Balakrishnan K, Adair-Rohani H, Balmes J, Chafe Z, Dherani M, Hosgood HD, Mehta S, Pope D. Millions dead: how do we know and what does it mean? Methods used in the comparative risk assessment of household air pollution. Annu Rev Public Health. 2014;35:185-206.

18. Secretary Clinton Announces Global Alliance for Clean Cookstoves. http:// cleancookstoves.org/about/news/09-26-2010-secretary-clinton-announcesglobal-alliance-forclean-cookstoves.html.

19. Smith-Sivertsen T, Diaz E, Pope D, Lie RT, Diaz A, McCracken J, Bakke P, Arana $B$, Smith KR, Bruce N. Effect of reducing indoor air pollution on women's respiratory symptoms and lung function: the RESPIRE randomized trial, Guatemala. Am J Epidemiol. 2009;170(2):211-20.

20. Smith KR, McCracken JP, Thompson L, Edwards R, Shields KN, Canuz E, Bruce N. Personal child and mother carbon monoxide exposures and kitchen levels: methods and results from a randomized trial of woodfired chimney cookstoves in Guatemala (RESPIRE). J Expo Sci Environ Epidemiol. 2009;20(5):406-16.

21. Smith KR: Letter to the editor: response to "too many cookstoves spoil the effort to cut indoor air pollution". In: Washington Post vol April 18, 2012; 2012 
22. Dupas P. Getting essential health products to their end users: subsidize, but how much? Science. 2014;345(6202):1279-81.

23. Mobarak AM, Dwivedi P, Bailis R, Hildemann L, Miller G. Low demand for nontraditional cookstove technologies. Proc Natl Acad Sci. 2012;109(27): 10815-20.

24. World Bank: World development report 2015: mind, society, and behavior. Washington D.C.: World Bank Group; 2015.

25. Dupas $P$, Miguel E: Chapter 1 - Impacts and determinants of health levels in low-income countries. In: Handbook of Economic Field Experiments Volume 2, edn. Edited by Banerjee AV, Duflo E: North-Holland; 2017: 3-93.

26. Bagwell K, Riordan MH. High and declining prices signal product quality. Am Econ Rev. 1991:224-39.

27. Bollinger B, Gillingham K. Peer effects in the diffusion of solar photovoltaic panels peer effects in the diffusion of solar photovoltaic panels. Mark Sci. 2012;31(6):900-12.

28. Manski CF. Identification of endogenous social effects: the reflection problem. Review of Economic Studies. 1993;60(3):531-42.

29. Bobonis GJ, Finan F. Neighborhood peer effects in secondary school enrollment decisions. Review of Economics and Statistics. 2009;91(4): 695-716.

30. Kahneman D, Tversky A. Prospect theory: an analysis of decision under risk Econometrica: Journal of the Econometric Society. 1979:263-91.

31. Oduro AR, Wak G, Azongo D, Debpuur C, Wontuo P, Kondayire F, Welaga P, Bawah A, Nazzar A, Williams J. Profile of the Navrongo health and demographic surveillance system. Int J Epidemiol. 2012;41(4):968-76.

32. Drilling in gung-ho Greeley, hits opposition near west-side homes.

33. Dickinson KL, Kanyomse E, Piedrahita R, Coffey E, Rivera I, Adoctor J, Aligiria R, Muvandimwe D, Dove M, Dukić V, et al. Research on emissions, air quality, climate, and cooking Technologies in Northern Ghana (REACCTING): study rationale and protocol. BMC Public Health. 2015;15:126.

34. Pennise D, Brant S, Agbeve SM, Quaye W, Mengesha F, Tadele W, Wofchuck T. Indoor air quality impacts of an improved wood stove in Ghana and an ethanol stove in Ethiopia. Energy for Sustainable Development. 2009;13(2):71-6.

35. Jetter J, Zhao Y, Smith KR, Khan B, Yelverton T, DeCarlo P, Hays MD. Pollutant emissions and energy efficiency under controlled conditions for household biomass Cookstoves and implications for metrics useful in setting international test standards. Environmental Science \& Technology. 2012;46(19):10827-34.

36. Dickinson $\mathrm{KL}$, Hsu Y-Y, Kanyomse E, Oduro AR. Where There's smoke...: measuring preferences for improved Cookstove attributes using choice experiments in northern Ghana. In: preparation; 2014.

37. Krishna V: Auction theory: academic press; 2009.

38. Kanninen BJ. Optimal design for multinomial choice experiments. J Mark Res. 2002;39(2):214-27.

39. Lazari AG, Anderson DA. Designs of discrete choice set experiments for estimating both attribute and availability cross effects. J Mark Res. 1994; 31(3):375-83.

40. Ferrini S, Scarpa R. Designs with a priori information for nonmarket valuation with choice experiments: a Monte Carlo study. J Environ Econ Manag. 2007;53(3):342-63.

41. Ruiz-Mercado I, Canuz E, Smith KR. Temperature dataloggers as stove use monitors (SUMs): field methods and signal analysis. Biomass Bioenergy. 2012;47:459-68.

42. Piedrahita R, Dickinson KL, Kanyomse E, Coffey E, Alirigia R, Hagar Y, Rivera I, Oduro A, Dukić V, Wiedinmyer $C$, et al. Assessment of cookstove stacking in northern Ghana using surveys and stove use monitors. Energy for Sustainable Development. 2016;34:67-76.

43. Piedrahita R, Kanyomse E, Coffey E, Xie M, Hagar Y, Alirigia R, Agyei F, Wiedinmyer C, Dickinson KL, Oduro A, et al. Exposures to and origins of carbonaceous PM2.5 in a cookstove intervention in northern Ghana. Sci Total Environ. 2017;576:178-92.

44. Piedrahita R: On the assessment of air pollution and behavior within a Cookstove intervention study in northern Ghana and development of improved measurement techniques. ProQuest dissertations publishing: University of Colorado boulder; 2017.

45. Nexleaf Analytics: Transparent climate and health metrics: An open data dashboard and wireless platform for cookstove monitoring. In.: Asia Sustainable and Alternative Energy Program; 2017.
46. Ezzati M, Kammen DM. The health impacts of exposure to indoor air pollution from solid fuels in developing countries: knowledge, gaps, and data needs. Environ Health Perspect. 2002;110(11):1057.

47. Dons E, Panis LI, Van Poppel M, Theunis J, Willems H, Torfs R, Wets G. Impact of time-activity patterns on personal exposure to black carbon. Atmos Environ. 2011:45(21):3594-602.

48. De Nazelle A, Seto E, Donaire-Gonzalez D, Mendez M, Matamala J, Nieuwenhuijsen MJ, Jerrett M. Improving estimates of air pollution exposure through ubiquitous sensing technologies. Environ Pollut. 2013;176:92-9.

49. Buonanno G, Stabile L, Morawska L. Personal exposure to ultrafine particles: the influence of time-activity patterns. Sci Total Environ. 2014;468:903-7.

50. Steinle S, Reis S, Sabel CE, Semple S, Twigg MM, Braban CF, Leeson SR, Heal MR, Harrison D, Lin C. Personal exposure monitoring of PM2. 5 in indoor and outdoor microenvironments. Sci Total Environ. 2015;508:383-94.

51. Allen-Piccolo G, Rogers JV, Edwards R, Clark MC, Allen TT, Ruiz-Mercado I, Shields KN, Canuz E, Smith KR. An ultrasound personal locator for timeactivity assessment. Int J Occup Environ Health. 2009;15(2):122-32.

52. Wiedinmyer C, Dickinson K, Piedrahita R, Kanyomse E, Coffey E, Hannigan M, Alirigia R, Oduro A. Rural-urban differences in cooking practices and exposures in northern Ghana. Environ Res Lett. 2017;12(6):065009.

53. Train KE: Discrete choice methods with simulation: Cambridge university press; 2009.

54. Mortimer K, Ndamala CB, Naunje AW, Malava J, Katundu C, Weston W, Havens D, Pope D, Bruce NG, Nyirenda M, et al. A cleaner burning biomassfuelled cookstove intervention to prevent pneumonia in children under 5 years old in rural Malawi (the cooking and pneumonia study): a cluster randomised controlled trial. Lancet. 2017;389(10065):167-75.
Ready to submit your research? Choose BMC and benefit from:
- fast, convenient online submission
- thorough peer review by experienced researchers in your field
- rapid publication on acceptance
- support for research data, including large and complex data types
- gold Open Access which fosters wider collaboration and increased citations
- maximum visibility for your research: over $100 \mathrm{M}$ website views per year
At BMC, research is always in progress.
Learn more biomedcentral.com/submissions 